\title{
The ISBSG Software Project Repository: An Analysis from Six Sigma Measurement Perspective for Software Defect Estimation
}

\author{
Mhammed Almakadmeh, Alain Abran \\ École de Technologie Supérieure, Université du Québec, Montréal, Canada \\ Email: mhammed.almakadmeh.1@ens.etsmtl.ca, alain.abran@etsmtl.ca
}

How to cite this paper: Almakadmeh, M. and Abran, A. (2017) The ISBSG Software Project Repository: An Analysis from Six Sigma Measurement Perspective for Software Defect Estimation. Journal of Software Engineering and Applications, 10, 693-720. https://doi.org/10.4236/jsea.2017.108038

Received: May 22, 2017

Accepted: July 8, 2017

Published: July 11, 2017

Copyright ( 92017 by authors and Scientific Research Publishing Inc. This work is licensed under the Creative Commons Attribution International License (CC BY 4.0).

http://creativecommons.org/licenses/by/4.0/

\begin{abstract}
The International Software Benchmarking Standards Group (ISBSG) provides to researchers and practitioners a repository of software projects' data that has been used to date mostly for benchmarking and project estimation purposes, but rarely for software defects analysis. Sigma, in statistics, measures how far a process deviates from its goal. Six Sigma focuses on reducing variations within processes, because such variations may lead to an inconsistency in achieving projects' specifications which represent "defects", which mean not meeting customers' satisfaction. Six Sigma provides two methodologies to solve organizations' problems: "Define-Measure-Analyze-Improve-Control" process cycle (DMAIC) and Design of Six Sigma (DFSS). The DMAIC focuses on improving the existed processes, while the DFSS focuses on redesigning the existing processes and developing new processes. This paper presents an approach to provide an analysis of ISBSG repository based on Six Sigma measurements. It investigates the use of the ISBSG data repository with some of the related Six Sigma measurement aspects, including Sigma defect measurement and software defect estimation. This study presents the dataset preparation consisting of two levels of data preparations, and then analyzed the quality-related data fields in the ISBSG MS-Excel data extract (Release 12 - 2013). It also presents an analysis of the extracted dataset of software projects. This study has found that the ISBSG MS-Excel data extract has a high ratio of missing data within the data fields of "Total Number of Defects" variable, which represents a serious challenge when the ISBSG dataset is being used for software defect estimation.
\end{abstract}

\section{Keywords}

ISBSG, Six Sigma, Defect Estimation, DMAIC, Design for Six Sigma, COSMIC Function Points 


\section{Introduction}

Six Sigma has achieved recognizable success over the past 20 years in industry in general, while only a few studies have been conducted within the software industry to explore its use and expected benefits. In particular, there is a lack of Six Sigma related empirical studies based on large repository of software project data such as the repositories of the International Software Benchmarking Standards Group (ISBSG).

Since the 1980's, Six Sigma is registered as a trademark of Motorola in the USA (Motorola, 2004). It is based on the Edwards Deming's Plan-Do-Check-Act cycle [1]. Six Sigma is considered as a data-driven suite of improvement methodologies based on a common philosophy and it is supported by tools for measurements and for process and product improvement [2]. Six Sigma involves a long term commitment that requires a full commitment from upper management in the organization to change decision making strategies [3]. In the last 20 years, the use of Six Sigma has increased in different industries [3].

One of the major differences between Six Sigma and other quality initiatives is that it involves a project by project approach of implementation [4]. Six Sigma focuses on both management and technical components [5]:

A. The management components involve to select the right people for Six Sigma projects, to select the right process measures, to provide resources for Six Sigma training, to provide clear direction to project selection, etc. [5].

B. The technical components focus on process improvements by reducing variation using certain statistical tools and techniques adopted for problem solving purposes [5].

Six Sigma can help organizations to improve their business processes and bottom-line issues: Six Sigma implementation involves determining customer's requirements and defining defects in terms of their "critical to quality" parameters [6].

The success of Six Sigma in different industries over the last two decades has encouraged exploring Six Sigma applications in other industries, such as the software industry [1] [7] [8] [9] [10] and [11]. Although Six Sigma has been adopted by many industries, it still considered new in the software industry [5].

Few research studies on Six Sigma have been published in the software literature: on the one hand, some challenge whether Six Sigma can be indeed relevant to software organizations [8], while other such as [5] [12] claim that Six Sigma can bring large benefits to software organizations.

The International Software Benchmarking Standards Group (ISBSG) was founded in 1994 by a number of national software measurement associations [13] to:

- Develop "the profession of software measurement by establishing a common vocabulary and understanding of terms".

- Provide "software development practitioners with industry output standards against which they can compare their aggregated or individual projects, and real data of international software development that can be analyzed to help 
improve the management of IT resources by both business and government" [14].

The ISBSG dataset provides "software development practitioners with industry output standards against which they may compare their aggregated or individual projects, and real data of international software development that can be analyzed to help improve the management of Information Technology (IT) resources by both business and government" [15].

The data collected using the ISBSG data collection questionnaire are assembled, evaluated, and stored in a database in Australia. A standardized extract of a number of data fields in this database is provided for a fee in the format of a Release; moreover, in addition to these ISBSG Releases, special extracts of additional data fields are available upon a specific request for research purposes [16].

The ISBSG database of software projects is a multi-organizational and multi-environment dataset with more than 100 data fields on more than 6000 projects from industry and public organizations, the majority of which were collected after 2001; these projects are related either to software development and software enhancements and from various software industry sectors [16].

The ISBSG repository collects a large number of independent variables and a considerable amount of descriptive information on the various characteristics of software projects, including quality-related data fields, through the software life cycle phases [17].

The data fields include, for instance, information about project staffing, effort by phase, development methods and techniques, team work, project type, organization type, software process along with the various life cycle phases, technology and tools used for developing and carrying out the project, people and work effort for each project team member, software product, quality attributes, size attributes, and so on [16].

The International Software Benchmarking Standards Group (ISBSG) provides to researchers and practitioners a repository of software projects' data that has been used to date mostly for benchmarking and project estimation purposes, but rarely for software defects analysis. Sigma, in statistics, measures how far a process deviates from its goal. Six Sigma focuses on reducing variations within processes, because such variations may lead to an inconsistency in achieving projects' specifications which represent "defects", which means not meeting customers' satisfaction. Six Sigma provides two methodologies to solve organizations' problems: "Define-Measure-Analyze-Improve-Control” process cycle (DMAIC) and Design of Six Sigma (DFSS). This paper investigates the use of the ISBSG data repository with some of the related Six Sigma measurement aspects, including Sigma defect measurement and software defect estimation.

The rest of this paper is structured as follows. Section 2 presents overview of Six Sigma from the scientific research literature in software and in general: Six Sigma definitions, concepts, and the statistical toolkits.

Section 3 presents an overview of the ISBSG data repository, including the ISBSG internal view, the anonymity of the data collected and the ISBSG data ex- 
tract release 12 of 2013.

Section 4 presents the quality-related information in the ISBSG questionnaire, and conducts a mapping of the ISBSG questionnaire to the related measurement steps in Six Sigma (DMAIC and DFSS) methodologies. It presents the data set preparation which consists of two levels of data preparation based on [18], and next analyzes the quality-related data fields in the ISBSG MS-Excel data extract (Release 12 - 2013). It also presents an analysis of the extracted software projects of the ISBSG dataset.

Finally, section 5 summarizes the research findings and recommendations, and suggests a number of the future related research challenges.

\section{Six Sigma-Overview}

Six Sigma has evolved over the last two decades and its definition can have different meanings. For instance, Six Sigma has been extended to three levels in [19]:

- a measurement system;

- a methodology:

- DMAIC which stands for "Define-Measure-Analyze-Improve-Control", and

- DFSS which stands for "Design for Six Sigma".

- a management system.

The Six Sigma approach satisfies all three levels at the same time. This paper focuses on two perspectives of interest: as a Sigma level and as related measurement steps in improvement methodologies (DMAIC and DFSS).

\subsection{Six Sigma as a Measurement System}

Six Sigma can be defined as a statistical expression which measures the quality of meeting customer's requirements. “The term 'Sigma' is often used as a scale for levels of 'goodness' or quality”. Using this scale, 'Six Sigma' equates to 3.4 defects per one million opportunities (DPMO) [19]. Figure 1 illustrates how Six Sigma measures quality. In Figure 1 for example, when $30.9 \%$ of products are without defects, the Sigma level is 1 ; and when $99.9997 \%$ of products are without defects, the Sigma level is 6. Fewer defects correspond to higher level of Sigma, and thus higher level of customer satisfaction: each additional Sigma level corresponds to an exponential reduction in defects [20].

Figure 1 illustrates a process that is centered with a normality distribution with mean $(\mu)$ aligned with target $(T)$, and the specifications located six standard deviations on to the mean sides [2].

The "sigma level" corresponds to "where a process or product performance falls when compared to customer specifications. In other words, the difference between the upper and lower bounds of the customer specification (denoted by the Lower Specification Limit, or LSL, and Upper Specification Limit, or USL) represents the range within which the process, product or service must fall in order to meet customer specifications, with optimal design or target $(T)$ at the center" [2]. 


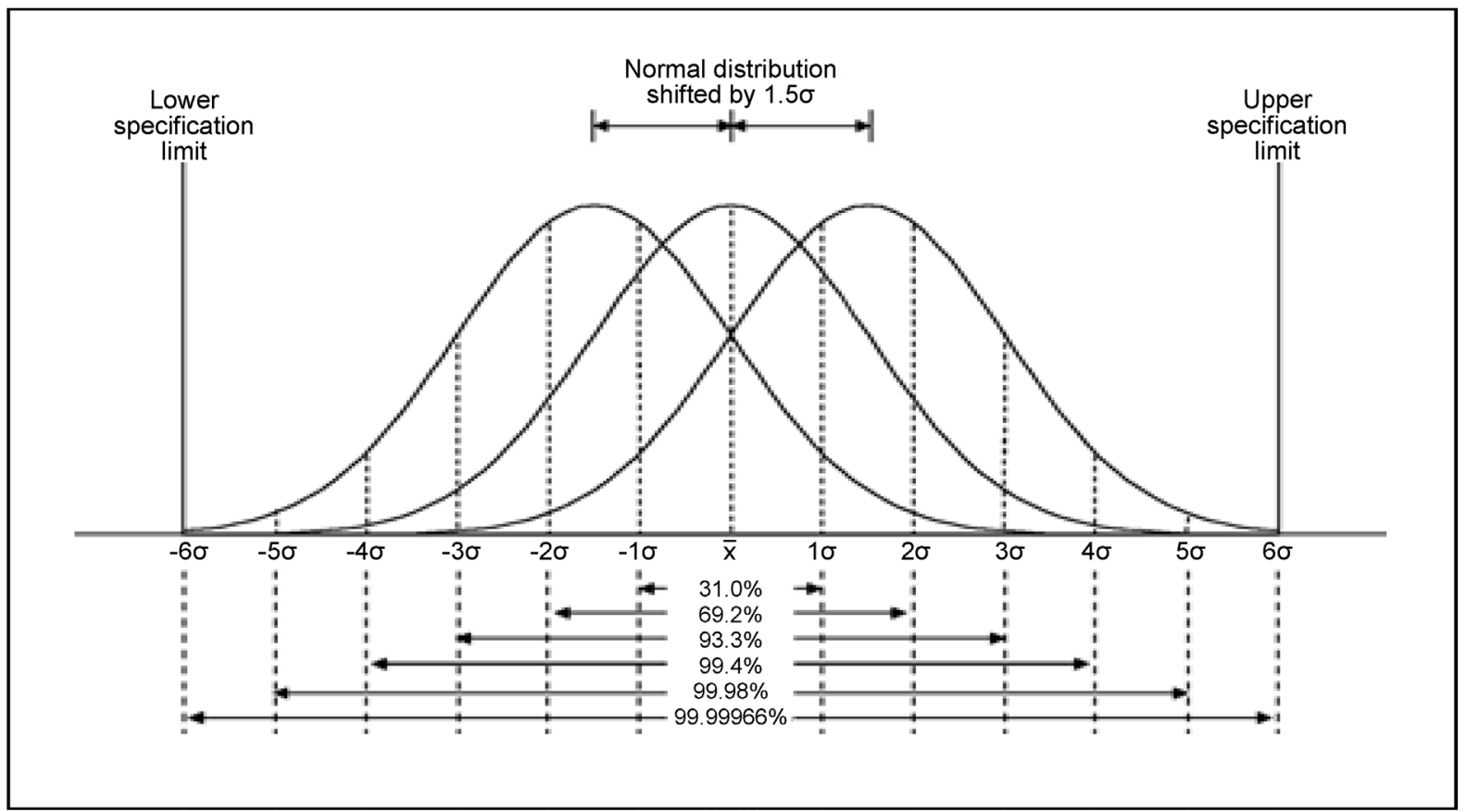

Figure 1. How six sigma measures quality [21].

The key measurements used in Six Sigma include [2]:

- Critical to quality (CTQ),

- Mean $(\mu)$,

- Standard deviation $(\delta)$,

- The common Six Sigma Defect measures such as: Defect rate: Defects Per Unit (DPU) or Defect Density (DD), Sigma level, Process capability indices $\left(C_{P}, C_{P k}\right)$, and Yield.

As result to the natural drifting that can occur in the process execution, it is observed that it over time the process mean drifts from the target by 1.5 -standard deviation [2]: therefore, the long-term standard deviation of the process will be greater than the observed one on the short-term [22]. In other words, when a process fits on " 6 sigma" between the process mean and one of the nearest specification limit in a short-term data variation, it will be " 4.5 sigma" in the long term fit. So the six sigma process in fact corresponds to " 4.5 sigma" referred to as "6 sigma" minus the 1.5-sigma shift [22]. The long-term data variation, on the other hand, contains common cause variations and special cause variations [23]. However the short-term data variation does not contain the special cause variation, so basically, it will have a higher process capability than the long-term data variation [23].

\subsection{Six Sigma as a Problem Solving Methodology}

Six Sigma provides two methodologies to solve organizations' problems: DMAIC and Design of Six Sigma (DFSS).

\subsubsection{Six Sigma DMAIC}

DMAIC stands for: "Define-Measure-Analyze-Improve-Control" process cycle 
[4] and is summarized in Table 1. Six Sigma DMAIC involves process improvement that can be achieved through a systematic approach for reducing variation and defects of existing processes.

\subsubsection{Design for Six Sigma (DFSS)}

Design for Six Sigma (DFSS) is a Six Sigma approach that involves designing new or re-designing processes and products at early stages of the life cycle [4]. Most DFSS training courses and textbooks divide the process into between four to six phases [24]: they may vary within the steps included on each one [24]; however, they all have similar objectives and goals [2] [24] [25]. This study adopts the Chowdhury's framework of IDDOV; however, it must be noted that IDDOV will be treated as five process cycle phases [24]: Identification-DesignDevelopment-Optimization-Verification-see Table 2.

Besides the IDDOV framework, there are other DFSS frameworks such as:

- Define, Measure, Analyze, Design, Verify (DMADV)

- Concept, Design, Optimize, Verify (CDOV)

- Define, Measure, Analyze, Design, Optimize, Verify (DMADOV)

The Six Sigma of DMAIC and DFSS methodologies are complementary strategies and employ some of the same tools and techniques [24]. However, there are differences between them and Table 3 outlines those differences [24]. When deciding whether to use DFSS techniques or the traditional Six Sigma DMAIC it

Table 1. DMAIC process [20].

\begin{tabular}{|c|c|}
\hline Steps & Key processes \\
\hline \multirow{3}{*}{ Define } & Define the requirements and expectations of the customer. \\
\hline & Define the project boundaries. \\
\hline & Define the process by mapping the business flow. \\
\hline \multirow{3}{*}{ Measure } & Measure the process to satisfy customer's needs. \\
\hline & Develop a data collection plan. \\
\hline & Collect and compare data to determine issues and shortfalls. \\
\hline \multirow{3}{*}{ Analyze } & Analyze the causes of defects and sources of variation. \\
\hline & Determine the variations in the process. \\
\hline & Prioritize opportunities for future improvement. \\
\hline \multirow{2}{*}{ Improve } & Improve the process to eliminate variations. \\
\hline & Develop creative alternatives and implement enhanced plan. \\
\hline \multirow{3}{*}{ Control } & Control process variations to meet customer requirements. \\
\hline & Develop a strategy to monitor and control the improved process. \\
\hline & Implement the improvements of systems and structures. \\
\hline
\end{tabular}

Table 2. IDDOV process [24].

\begin{tabular}{|c|c|}
\hline Steps & Key processes \\
\hline Identification & Identify the opportunity and Define the requirements. \\
\hline Design & Define initial design. \\
\hline Development & $\begin{array}{l}\text { Develop the high level design concepts and design alternatives to select the best } \\
\text { design. }\end{array}$ \\
\hline \multicolumn{2}{|c|}{ Optimization Optimize the design. Develop plans for test verification; this may require simulations. } \\
\hline Verification & Verify the design. Implement the process in operational scale. \\
\hline
\end{tabular}


Table 3. Differences between six sigma DMAIC and DFSS [24].

\begin{tabular}{ccc}
\hline Element & Six Sigma & DFSS \\
\hline Focus & Existing process & New process \\
Goal & Reduce variation & Reduce variation and optimize performance \\
Action taken & Analyze & Design \\
Best suited for & Maximizing current process & Developing new products or reengineering \\
Major effect is on & $C_{P}$ (reducing variation) & $C_{P k}$ (centering within customer requirements) \\
\hline
\end{tabular}

is important to consider whether the project involves a new process or an existing one [24]: DFSS is best employed on new products and processes, while the Six Sigma DMAIC is used to improve existing ones [24].

DFSS works on the Design phase in the software life cycle, while the DMAIC comes after the Design phase of the software development life cycle [24].

DFSS share the same goals with DMAIC, and can be represented as a continuing step to Six Sigma DMAIC; it also provides a set of tools and techniques that help to reduce variation in the process design [24]. The DFSS is an addition to DMAIC initiatives, not a replacement. The expected process Sigma level for a DFSS product is at least 4.5 [24] [25].

The goal of Six Sigma is to have processes or products that are almost defect free: achieving this goal is not as simple as it sounds [24]: it requires hard working and full commitment from the organizations' top management. However, it is possible for organizations that follow the DMAIC model to adopt Six Sigma tools as their statistical toolkit [24].

\subsection{Tools and Techniques in Six Sigma}

Tools used in Six Sigma include qualitative and quantitative (statistical) tools for data analysis, root cause analysis, root cause validation, and identification and selection of process improvements [2]:

- Qualitative tools refer to: process mapping, fishbone diagram, cause and effect matrix, failure mode effects analysis (FMEA), etc.

- Quantitative tools refer to: Kruskal-Wallis, one- and two-sample T-test, analysis of variance, confidence intervals, F-tests, one- and two-proportion tests, Monte Carlo simulation, regression, Design of Experiments (DOE), etc.

\section{The International Software Benchmarking Standards Group (ISBSG)}

\subsection{ISBSG Data Repository-Overview}

In software engineering, the data collected for empirical studies is very important. Data repositories such as the ISBSG provides a free set of questionnaires to collect data on software projects, including software functional size measured with measurement methods recognized by ISO. ISBSG collects data in a repository and provides an extract of data to practitioners and researchers in a MS-Excel file-see Figure 2. 


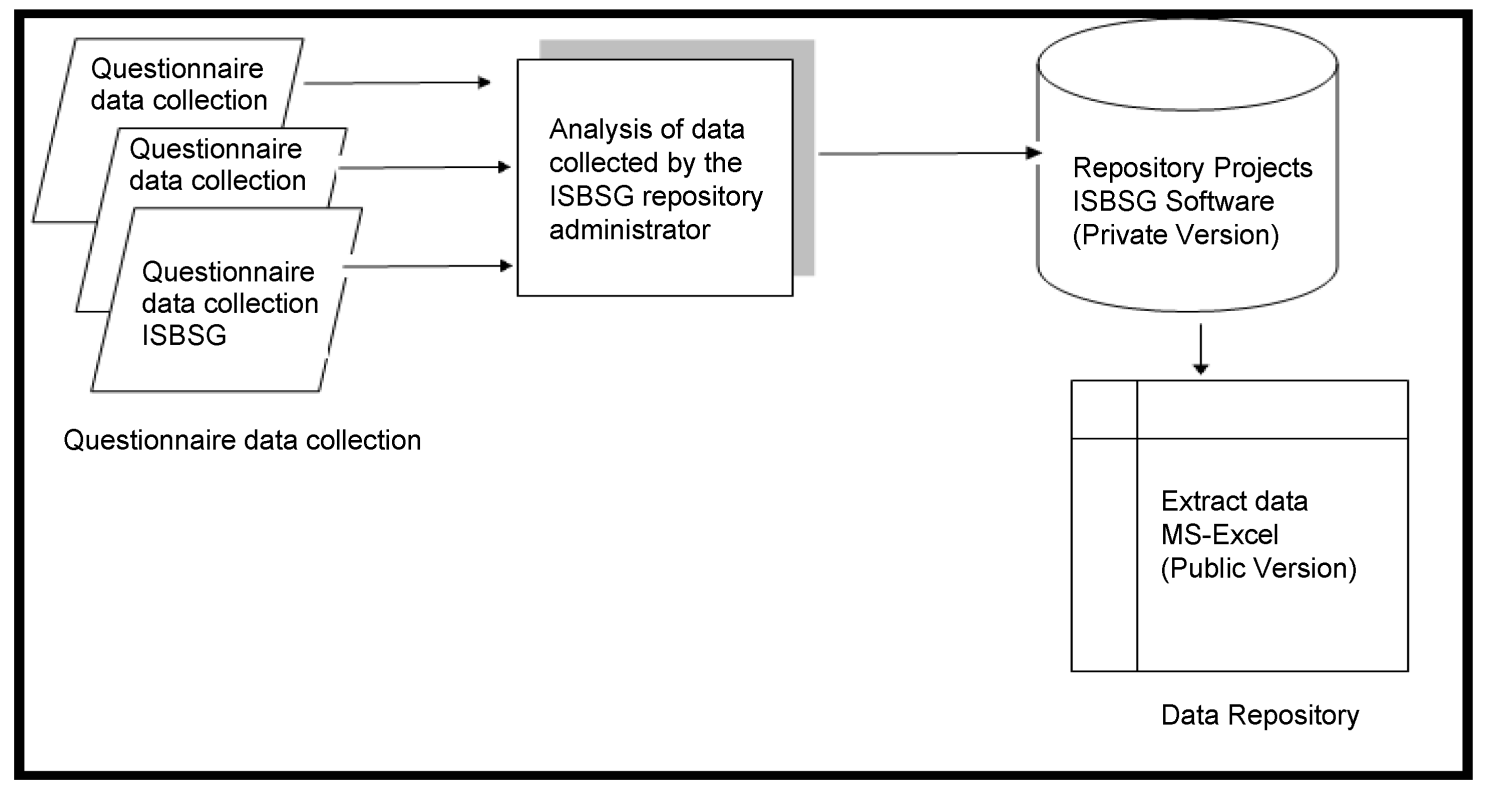

Figure 2. Management of the ISBSG repository [17].

The data collection questionnaire is available on the ISBSG website (http://isbsg.org/data-collection-questionnaires/) and includes a large number of quantitative and descriptive information on the different characteristics of a software project, namely: team project effort by phase of development, the development methods and techniques, etc.

ISBSG provides to its users a dictionary of the terms and measures it has defined to facilitate the understanding of the questionnaire, to assist in the collection of project data in the repository and to standardize the way that the data collected are analyzed [13]. The questionnaire consists of seven sections broken down into several sub-sections.

ISBSG offers at a modest license fee the public the data collected from various organizations around the world, with different methodologies, techniques and phases of the software life cycle, and in standard format [17]. For example, ISBSG provides useful data for multiple purposes, namely the comparison of productivity models, models for estimating the effort, etc. [17]. Such models can be used by organizations to improve their capacity in terms of planning and control of projects. In addition, the ISBSG repository collects a large number of numeric data on the different characteristics of the software project, including with its various project phases from planning to completion [17]. The ISBSG collects data related to software quality that span the entire software life cycle, from project initiation to project completion.

\subsection{ISBSG Internal View}

The internal view of the ISBSG data repository corresponds closely to their data collection questionnaire, with some additional fields added by their repository manager [26].

The data repository of the ISBSG [13] is a publicly available multi-company 
data set which contains software project data collected from various organizations around the world from 1989 on. This data set has been used in number of studies focusing on software estimation, such as in [13] to estimate software effort.

For example, the ISBSG provides data are related to:

- Defect prediction: such as number of defects recorded during the various software life cycle phases, effort, size in Function Points and LOC (Lines Of Code), number of requests for specification changes during the software life cycle, type of application, etc. [16].

- Effort prediction: such as effort by phases, summary work effort, normalized work effort, etc.

The ISBSG questionnaire contains six parts [26]:

- Project attributes

- Project work effort data

- Project size data (in Function Points)

- Project quality data

- Project cost data

- Project estimation data

For the purpose of software benchmarking, ISBSG collects, analyzes and reports data relating to products developed and processes implemented within organizational units in order to [26]:

- Support effective management of the processes.

- Objectively demonstrate the comparative performance of these processes.

The projects have been submitted from 25 countries and the major contributors are: the United States, Japan, Australia, Finland, Netherlands and Canada [13]. The data extract contains different types of projects: 61 percent are enhancements, 37 percent are new developments, and 2 percent are re-development projects.

The ISBSG offers 141 data fields in the data extract: they are not all necessarily filled out by the submitters since only a subset of the data fields is mandatory.

Software Functional Size is measured in Function Points. The four main Function Points measurement methods represented in the Repository are IFPUG, COSMIC, FiSMA and NESMA.

There are various data collection questionnaires of ISBSG data that have the same structure with a slight difference in Section "Functional size". In this research work the COSMIC functional sizing method has been selected. The COSMIC method can be used to measure the size of a change (addition, modification or deletion) to software of one CFP, and it can also be used to measure the size of software that is added, changed or deleted [27], whereas it is not possible to measure the size of a change to a software component with the IFPUG method for example: IFPUG can only be used to measure the size of software components that are added, changed or deleted [27].

The ISBSG data collection questionnaire includes 7 sections divided into subsections [27] - see Table 4 and Figure 3.

A. Submitter Information: collects the submitter's details, which are kept confidential to ISBSG. 
Table 4. Number of questions within the ISBSG COSMIC questionnaire.

\begin{tabular}{cc}
\hline Section & Number of questions \\
\hline Submitter information & 4 \\
Project process & 51 \\
Technology & 9 \\
People and work effort & 23 \\
Product & 7 \\
COSMIC project functional size & 30 \\
Project completion & 17 \\
Total & 141 \\
\hline
\end{tabular}

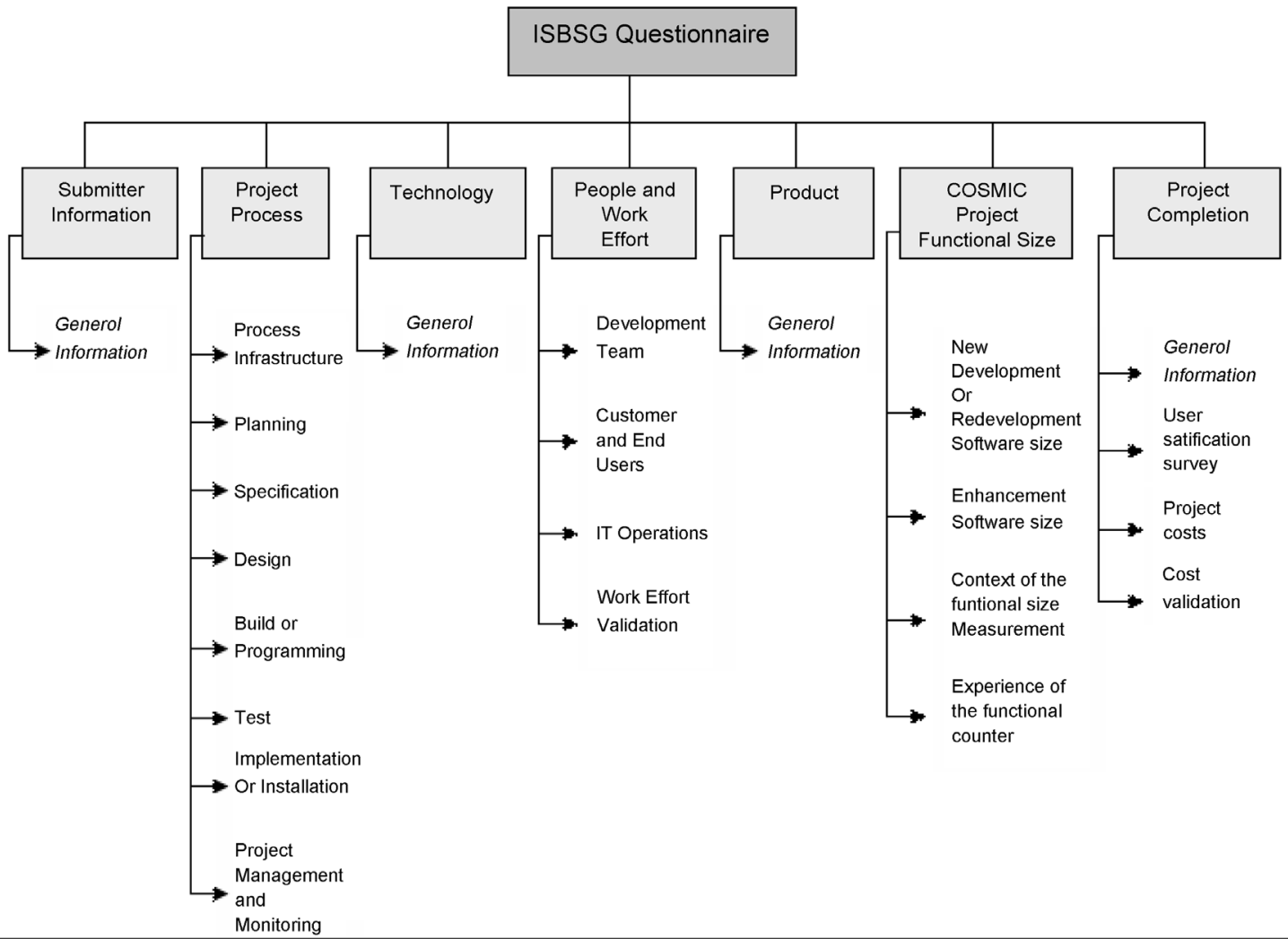

Figure 3. Structure of the ISBSG COSMIC data collection questionnaire [26].

B. Project Process: collects information about how the project was performed.

C. Technology: collects information about the technology used on the project.

D. People and Work Effort: collects descriptive information about the people who worked on the project and the effort they expended.

E. Product: collects description about the software product or application created or enhanced.

F. COSMIC Project Functional Size: collects the amount of functionality of the project delivered. The ISBSG COSMIC questionnaire collects quantitative information about data movements (ENTRIES, EXITS, WRITES and READS) by project types: new development, redevelopment software, or enhancement 
software.

G. Project Completion: collects overview information on the project completion.

(For more details: http://isbsg.org/data-collection-questionnaires/).

\subsection{Anonymity of the Data Collected}

The ISBSG recognizes the imperative of guaranteeing the anonymity of the organizations that submit data to its repositories. The ISBSG carefully follows a secure procedure to ensure that the sources of its data remain anonymous. Only submitters can identify their own projects/applications in the repositories using the unique identification key provided by the ISBSG manager on receipt of a submission.

\subsection{Extract Data from the ISBSG Data Repository}

The ISBSG assembles this data in a repository and provides a sample of the data fields to practitioners and researchers in an Excel file. All of the information on a project is reviewed by the ISBSG data administrator and rated in terms of data quality (from A to D). In particular, the ISBSG data administrator looks for omissions and inconsistencies in the data that might suggest that its reliability could be questioned.

For this study, the ISBSG data repository was selected in particular because the ISBSG collects data on the quality of software that spans the entire life cycle of a software project, from its inception to its completion.

\section{Data Preparation: ISBSG and Six Sigma}

\subsection{Quality-Related Information in the ISBSG Questionnaire}

The ISBSG data collection questionnaire [13] was analyzed in order to identify the data fields that collect information directly related to software quality. The data quality fields among the data collected in the Project Process category and the Project Completion category are listed in Appendix A. A number of data fields such as software size, number of defects are included in this list since they are useful for normalization purposes in order to calculate quality-related ratios, such as defect density.

From Appendix A, it can be observed that:

- The "Number of defects reported" is present in most of project phases (Q.27, Q.32, Q.38, Q.43, and Q.49) except the planning phase. For three ISBSG phases (e.g., build or programming, test, implementation or installation) and (Q.130) in the project completion category (e.g., the information collected for defects reported during the first month of the software operation by the users), the number of defects is classified into three defect levels (ISBSG 2013a):

- Minor defect: "Does not make the software unusable in any way".

- Major defect: "Causes part of the software to become unusable".

- Extreme defect: "Failure causing the software to become totally unusable". 
- The defects data fields correspond to the quality section in the ISBSG MS-Excel data extract structure-see Table 5.

- The "Number of change requests made" is also collected for most of project phases (Q.33, Q.39, Q.44, Q.50), that is from design to implementation or installation phases.

- The User Satisfaction Survey (Q.132) collects information about the satisfaction level as perceived by the end user, and the project cost collects information about Development team costs, Customer/End-user costs, and IT operation costs.

\subsection{Mapping the of ISBSG Questionnaire to Six Sigma Methodologies (DMAIC and DFSS)}

This section presents the detailed mappings between the six sigma methodologies of DMAIC and DFSS (IDDOV) with the ISBSG questionnaire data. The mapping of ISBSG questionnaire sections to Six Sigma for software is presented in Appendix B and Appendix C.

From Appendix B and Appendix C, it can be observed that:

$>$ The DMAIC for process improvement comes after the design stage of software development process, which focuses on enhancing the existed processes, whereas, the DFSS-IDDOV methodology comes before the design stage, which allows for re-designing processes before the implementation phase of projects process.

$>$ The DMAIC approach aligns with the software enhancement sub-section within the COSMIC Project Functional Size category.

The DFSS-IDDOV approach aligns with the software new development and re-development' sub-section within the COSMIC Project Functional Size category.

In contrast, questions (104, 105, 106, 107, 108, and 109) in Appendix C obtain information on functional size when to improve the existing processes (through adding, changing, or deleting functionalities).

$>$ Questions (98 and 99) collect the software functional size when to re-design existing process or designing new of processes.

In summary, the ISBSG data fields with information related to software quality have been identified which gives that 39 questions are related to software quality within the COSMIC sizing method questionnaire (Release 12 - 2013). The detailed mappings between the six sigma methodologies of DMAIC and DFSS (IDDOV) and the ISBSG data questionnaire have been conducted: it highlights

Table 5. Defect data fields in the ISBSG data extract [26].

\begin{tabular}{cc}
\hline Quality Fields & Description \\
\hline Minor defects delivered & Number of minor defects reported \\
Major defects delivered & Number of major defects reported \\
Extreme defects delivered & Number of extreme defects reported \\
Total defects delivered & Number of total defects reported (minor, major and extreme) \\
\hline
\end{tabular}


that DMAIC comes after the design stage at the process life cycle, whereas, DFSS comes early; it also shows that DMAIC aligns with software enhancement of software project type, and DFSS aligns with software new development and re-development of software project type.

\section{Application Analysis for the Proposed Approach to ISBSG}

\subsection{Analysis of the Quality-Related Data Fields in the ISBSG MS-Excel Data Extract (Release 12 - 2013)}

This section presents the data extraction of the ISBSG MS-Excel to be used in the next research phases. As recommended by [18] and [28] two verification steps have to be carried out before using the data set for analysis: data quality verification and data completeness verification.

\subsubsection{First Level of Data Preparation}

The first step of data quality verification is carried out by the ISBSG repository manager, who analyzes the data collected from the questionnaires and then rates the project data collected [17]. This rating information is recorded in a data field: the Data Quality Rating (DQR) with the following admissible values [17]:

- "A: the data submitted was assessed as being sound with nothing being identified that might affect its integrity.

- B: the submission appears fundamentally sound but there are some factors which could affect the integrity of the submitted data.

- C: due to significant data not being provided, it was not possible to assess the integrity of the submitted data.

- D: due to one factor or a combination of factors, little credibility should be given to the submitted data".

It is advisable for analysis purposes to consider only those projects having a $\mathrm{DQR}$ equal to $\mathrm{A}$ or $\mathrm{B}$ (e.g. the data collected have a high degree of integrity) [28]. The number of projects, with their corresponding data quality rating, is presented in Table 6 for ISBSG Release 12. The 448 projects with a C or D quality rating were dropped for our empirical analyses in the subsequent research phases: this left 5558 projects with an A or B data quality rating.

\subsubsection{Second Level of Data Preparation}

A second step is required in the data preparation. The quality-related data fields are not mandatory in the ISBSG repository and many software projects do not have data about defects.

Table 6. Project Data Quality Rating (DQR).

\begin{tabular}{ccc}
\hline Data Quality Rating (DQR) & No. of Projects & Percentage (\%) \\
\hline A & 1093 & 18.20 \\
B & 4465 & 74.34 \\
C & 255 & 4.25 \\
D & 193 & 3.21 \\
Total & 6006 & 100 \\
\hline
\end{tabular}


We applied next a further data filtering and analysis to select only projects sized with the COSMIC sizing method and which have data in the field of "Total number of defects": this left 393 COSMIC-sized software projects with a data quality rating $\mathrm{A}$ and $\mathrm{B}$.

Table 7 presents the number COSMIC-sized of projects with, or without, information about defects for a period of one month after of the software's operation, and categorized within [13] as: Minor Defects, Major Defects, and Extreme Defects, and Total Number of Defects.

The columns in Table 7 are on the number of projects with defect severity type's information correspond to:

- Blank data fields: represents the number of projects without any information.

- Non-Blank data fields: represents the number of projects with defect numbers.

- Zero Defect data fields: represents the number of projects with zero defects reported.

- Max Defect data fields: represents the maximum number of defects registered in the MS-Excel data extract for a defect severity type.

In particular, from Table 7:

- Blank or no recorded "total number of defects" = 311 software projects,

- With a "total number of defects" $=79$ software projects.

A zero value in the total number of defect field (e.g. total defects $=0$ ) $=33$ software projects. This might be real information, but the zero value might also be caused by poor data entry, and some organizations might have entered a zero value instead of leaving the field blank for a missing value. To be on the safe side for this analysis, these 33 projects are dropped from further analysis. This leaves 360 projects available for further quality-related analysis, where:

- 49 projects have data for "Total Number of Defects" (projects 1 to 49) and

- 311 projects have missing data (projects 50 and over).

Figure 4 shows the distribution of the software sizes of the data set of $N=360$ COSMIC-sized software projects, with a software size ranging from 2 to 2090 CFP (COSMIC Function Points), with most values at the low end. The median is 133 CFP.

\subsection{Analysis of Software Projects of ISBSG Dataset $N=360$ Projects}

\subsubsection{Software Projects' Development Type Analysis Results}

Figure 5 and Figure 6 present next the number of software projects by type and their percentage, where:

- Enhancement projects $=149$ projects, which represents $41 \%$ of projects number,

Table 7. Number of projects $(\mathrm{DQR}=\mathrm{A}$ and $\mathrm{B})$ by defect severity type.

\begin{tabular}{cccccc}
\hline Quality & Blanks & Non-Blanks & Zero Defect & Max Defect & Total \\
\hline Total Defects & 311 & 49 & 33 & 63 & 393 \\
\hline
\end{tabular}




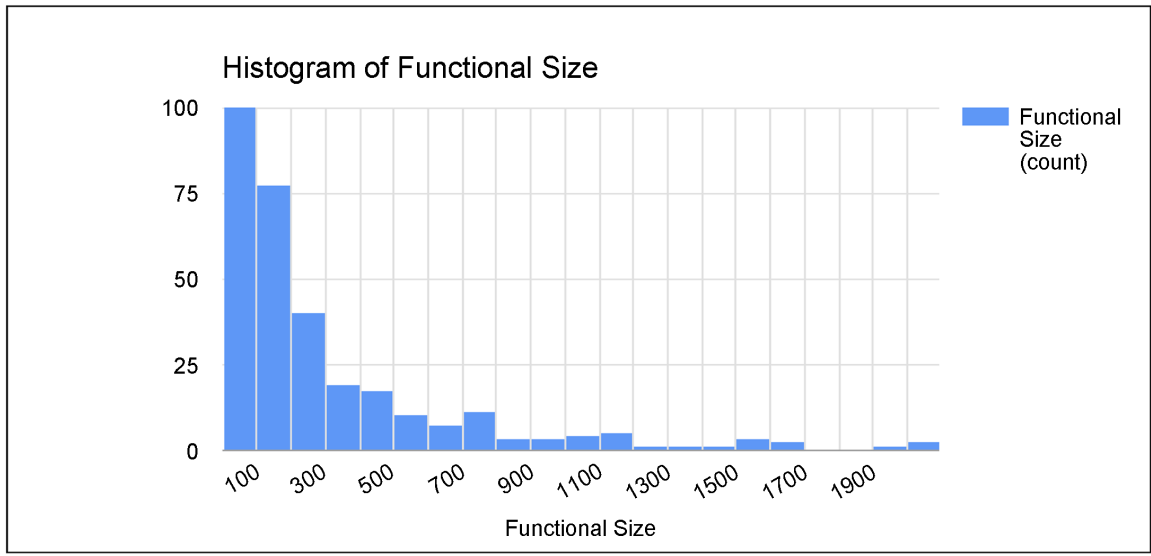

Figure 4. Distribution of the COSMIC functional size of data set $N=360$ projects.

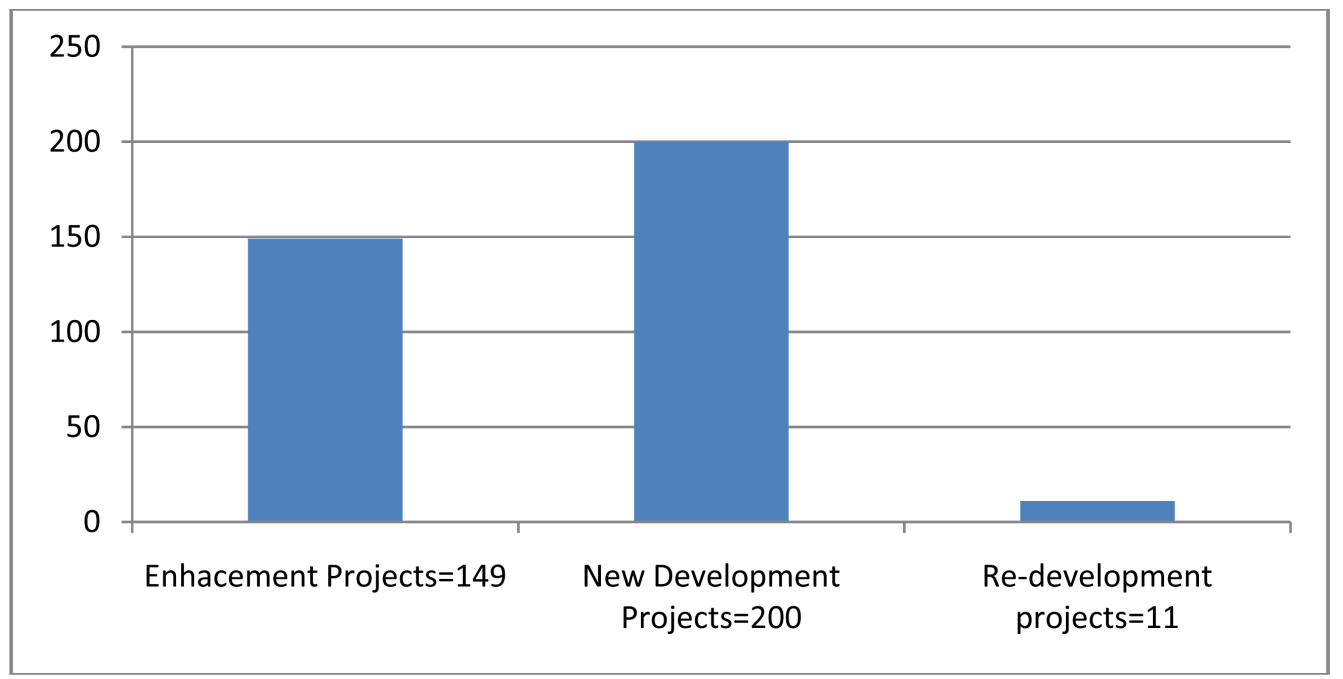

Figure 5. Number of software projects by type $N=360$ projects.

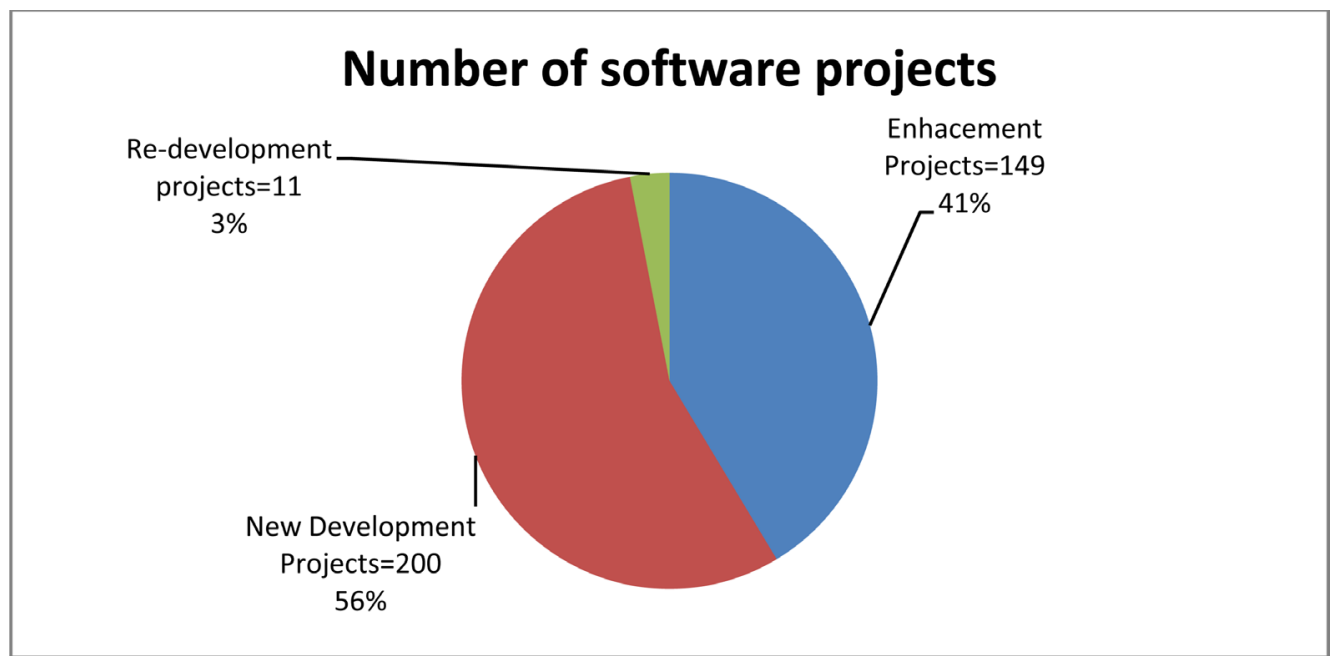

Figure 6. Number of software projects by type and their percentage $N=360$ projects.

- Re-development projects $=11$ projects, which represents $3 \%$ of projects number, and 
- New software development projects $=200$ projects, which represents the highest percentage of $56 \%$ of projects.

From the software projects' type distribution, it can be noted that software organizations have submitted more data on development of new processes or products (200 projects) than on the re-design of existing ones (11 projects). Therefore, this indicates that DFSS projects could be used for creating new processes or products (in order to prevent defects at early stages of software life cycle) more than seeking to re-design existing ones.

Based on Appendix B and Appendix C, Figure 7 presents an example of sample results for software projects of ISBSG data set $N=360$ with regards to software projects' development type and Sigma projects' type with their COSMIC functional size.

\subsubsection{Six Sigma Projects' Type Analysis}

Figure 8 and Figure 9 present the number of Sigma projects by type and their percentage, where the number of the DMAIC projects is 149 projects, which represents $41.4 \%$ of projects number, and the number of DFSS projects is 211 projects, which represents the highest percentage of $58.6 \%$.

Figure 10 shows the software sizes of DMAIC projects, with a range from 2 to 2003 CFP, with most values at the low end. The median size is 95 CFP.

Figure 11 shows the software sizes of DFSS projects, with a range from 8 to 2090 CFP, with most values at the low end. The median size is 175 CFP.

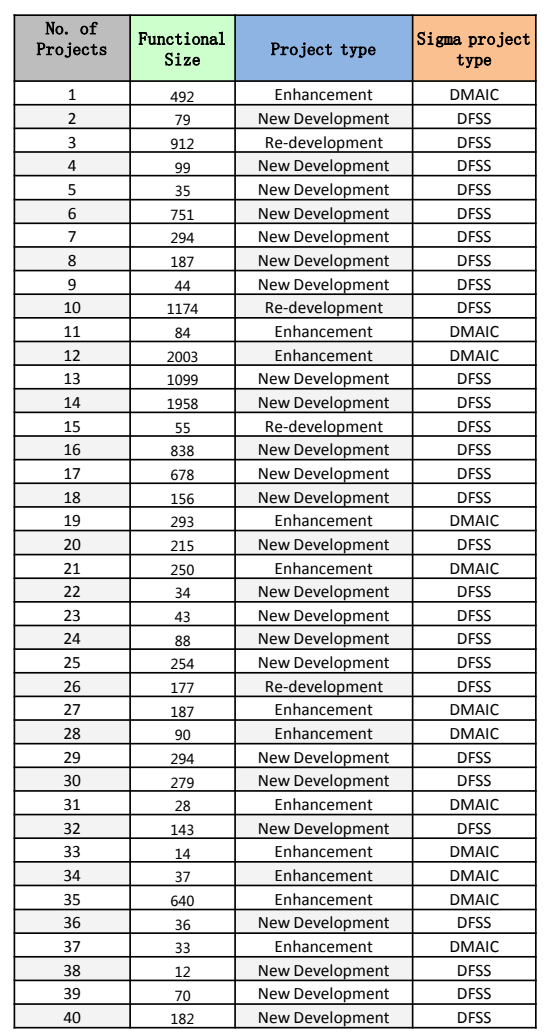

\begin{tabular}{|c|c|c|c|}
\hline $\begin{array}{c}\text { No. of } \\
\text { Projects }\end{array}$ & $\begin{array}{c}\text { Functional } \\
\text { Size }\end{array}$ & Project type & $\begin{array}{c}\text { Sigma project } \\
\text { type }\end{array}$ \\
\hline 41 & 11 & New Development & DFSS \\
\hline 42 & 1670 & New Development & DFSS \\
\hline 43 & 746 & Enhancement & DMAIC \\
\hline 44 & 186 & New Development & DFSS \\
\hline 45 & 23 & New Development & DFSS \\
\hline 46 & 579 & Enhancement & DMAIC \\
\hline 47 & 467 & Re-development & DFSS \\
\hline 48 & 86 & New Development & DFSS \\
\hline 49 & 441 & New Development & DFSS \\
\hline 50 & 297 & New Development & DFSS \\
\hline 51 & 183 & New Development & DFSS \\
\hline 52 & 568 & New Development & DFSS \\
\hline 53 & 108 & Enhancement & DMAIC \\
\hline 54 & 826 & New Development & DFSS \\
\hline 55 & 44 & Enhancement & DMAIC \\
\hline 56 & 121 & Enhancement & DMAIC \\
\hline 57 & 270 & New Development & DFSS \\
\hline 58 & 57 & New Development & DFSS \\
\hline 59 & 1384 & New Development & DFSS \\
\hline 60 & 36 & Enhancement & DMAIC \\
\hline 61 & 68 & Enhancement & DMAIC \\
\hline 62 & 135 & New Development & DFSS \\
\hline 63 & 93 & New Development & DFSS \\
\hline 64 & 94 & New Development & DFSS \\
\hline 65 & 142 & Enhancement & DMAIC \\
\hline 66 & 791 & Re-development & DFSS \\
\hline 67 & 748 & New Development & DFSS \\
\hline 68 & 273 & Enhancement & DMAIC \\
\hline 69 & 397 & Enhancement & DMAIC \\
\hline 70 & 44 & Enhancement & DMAIC \\
\hline 71 & 142 & New Development & DFSS \\
\hline 72 & 65 & New Development & DFSS \\
\hline 73 & 228 & New Development & DFSS \\
\hline 74 & 368 & New Development & DFSS \\
\hline 75 & 30 & New Development & DFSS \\
\hline 76 & 121 & Enhancement & DMAIC \\
\hline 77 & 72 & Enhancement & DMAIC \\
\hline 78 & 173 & Enhancement & DMAIC \\
\hline 79 & 60 & Enhancement & DMAIC \\
\hline 80 & 8 & New Development & DFSS \\
\hline & & & \\
\hline & & & \\
\hline 53 & & &
\end{tabular}

\begin{tabular}{|c|c|c|c|}
\hline $\begin{array}{c}\text { No. of } \\
\text { Projects }\end{array}$ & $\begin{array}{c}\text { Functional } \\
\text { Size }\end{array}$ & Project type & $\begin{array}{c}\text { Sigma project } \\
\text { type }\end{array}$ \\
\hline 81 & 198 & New Development & DFSS \\
\hline 82 & 15 & Enhancement & DMAIC \\
\hline 83 & 62 & New Development & DFSS \\
\hline 84 & 98 & New Development & DFSS \\
\hline 85 & 185 & New Development & DFSS \\
\hline 86 & 154 & New Development & DFSS \\
\hline 87 & 10 & New Development & DFSS \\
\hline 88 & 208 & New Development & DFSS \\
\hline 89 & 92 & New Development & DFSS \\
\hline 90 & 143 & Enhancement & DMAIC \\
\hline 91 & 60 & New Development & DFSS \\
\hline 92 & 624 & Enhancement & DMAIC \\
\hline 93 & 23 & Enhancement & DMAIC \\
\hline 94 & 346 & Enhancement & DMAIC \\
\hline 95 & 44 & Enhancement & DMAIC \\
\hline 96 & 202 & New Development & DFSS \\
\hline 97 & 81 & Enhancement & DMAIC \\
\hline 98 & 146 & Enhancement & DMAIC \\
\hline 99 & 216 & New Development & DFSS \\
\hline. &. & &. \\
\hline. &. & &. \\
\hline. &. & &. \\
\hline 360 & 108 & New Development & DFSS \\
\hline
\end{tabular}

Figure 7. An example of sample results for software projects of ISBSG data set $N=360$ with regards to software projects' development type, sigma projects' type. 


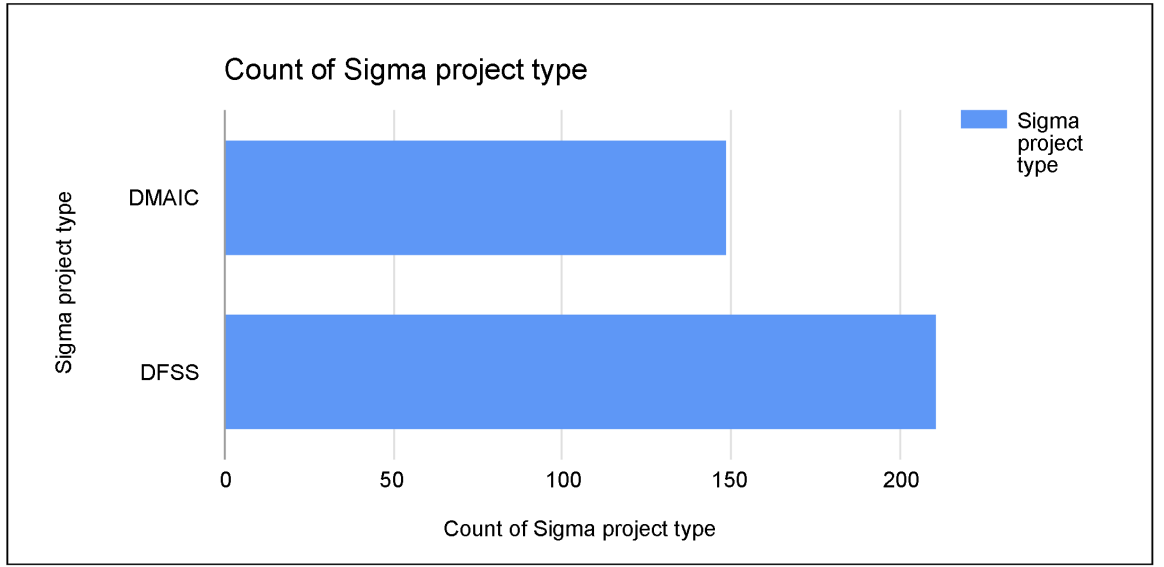

Figure 8. Number of sigma projects by type $-N=360$.

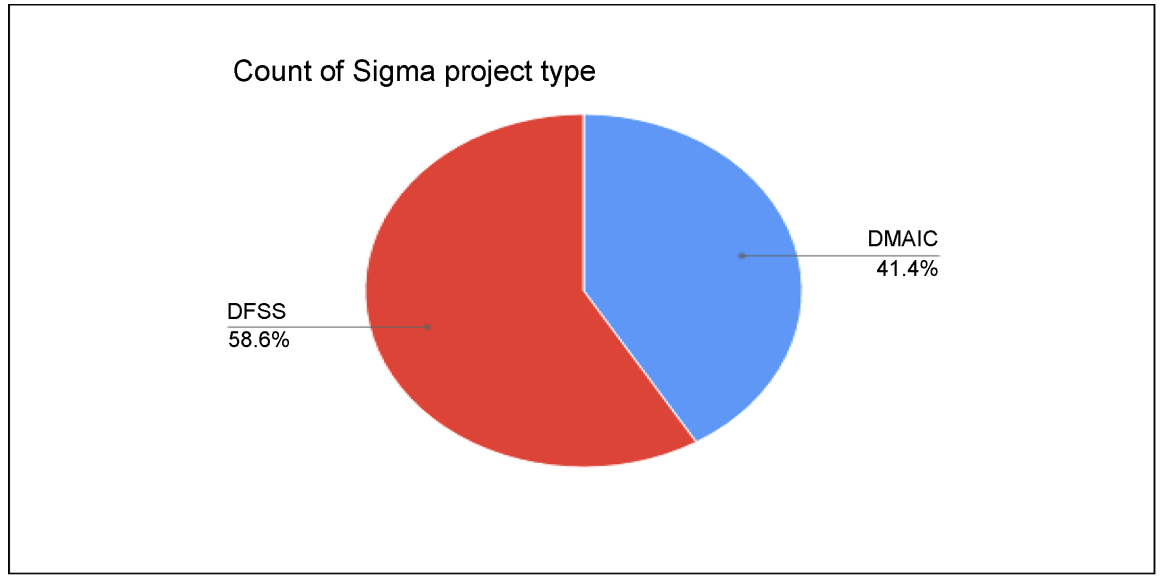

Figure 9. Number of sigma projects by type and their percentage $-N=360$.

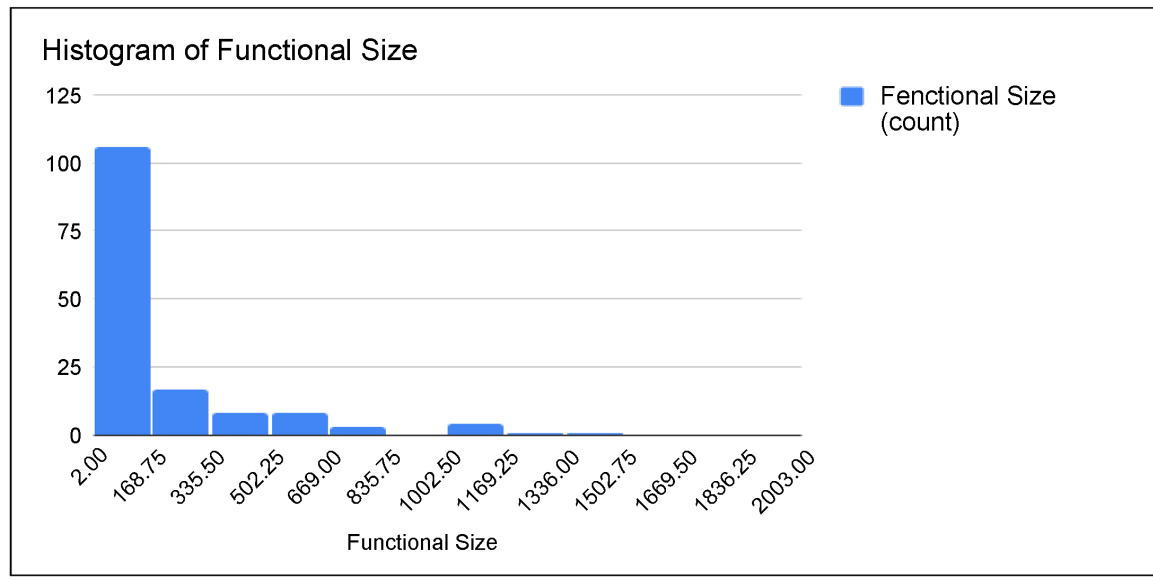

Figure 10. CFP software sizes of DMAIC projects $-N=149$.

The modeling through a linear regression of the relationship of the dependent variable "Total Number of Defects" (TD) based on an independent variable "Functional Size" in Function Points is used on the imputed dataset to obtain the TD estimates and standard errors (build TD estimation models).

The statistical analysis includes: 
- Estimate TD (dependent variable) based on Functional Size (independent variable).

- Analysis of TD with $R^{2}$ and $P$-value of the estimation results of TD using CFP as the dependent variable.

- Analyze the values of Defect Density (DD) for each software project within the dataset of $\mathrm{N}$ software projects based on the formula of the Defect Density which measures the quality of software in terms of defects delivered in unit size of software. It is expressed as Defects per Function Points (Defect/CFP).

The following criteria for analyzing the results of TD estimation models:

- Coefficient of determination $\left(R^{2}\right)$ : the coefficient has a value between 0 and 1 .

- Standard Errors (STD-E);

- $P$-value: Statistical Significance;

- $T$-test: Statistical Significance.

Given the complete data $N=49$ projects, the TD estimation model (based on the independent variable "Functional size") is built with both the complete data set $N=49$ projects-see Table 8 .

Table 8, displays a 95\% mean confidence interval and a $T$-test with the associated $P$-value and whether the independent variable "Functional size" has impact on the TD parameter estimates (of complete observations, $N=49$ projects): the inferences are based on the t-distribution, and followed by a graphical representation of "Total Number of Defects" based on "Functional Size"-see Figure 12.

Table 8 presents the results of the TD estimation model (to be used for generating predicted values as "imputes" for the missing TD) for the variable "Total Number of Defects" trained with the independent variables "Functional Size" for the imputation and based on the reported total defects of 49 projects.

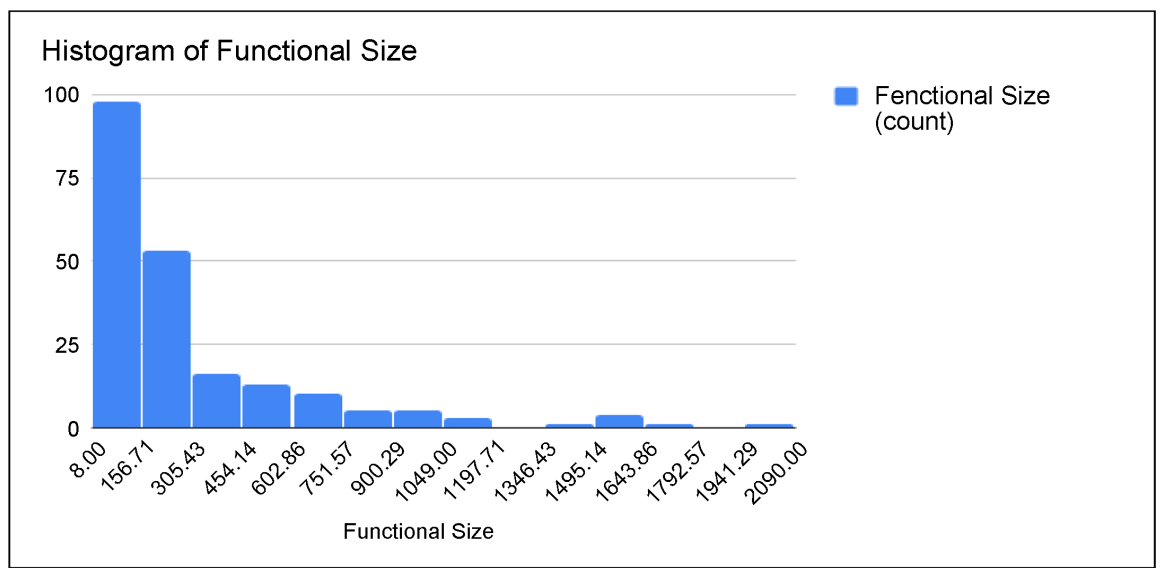

Figure 11. CFP software sizes of DFSS projects $-N=211$.

Table 8. Regression parameter analysis and statistical tests for TD estimation model based on the completed dataset $-N=49$.

\begin{tabular}{|c|c|c|c|c|c|c|c|c|}
\hline Variable & Intercept & t Coefficients & s R2 & 95\% Conf & fidence Limits & $T$-test & $\begin{array}{l}\text { Standard } \\
\text { Error }\end{array}$ & $P$-value \\
\hline Functional Size & 1.63 & 0.017 & 0.5 & 0.0113 & 0.0225 & 6.1 & 0.0028 & $1.95801 \mathrm{E}-07$ \\
\hline
\end{tabular}


Table 8 also shows the parameter estimates for the "Total Number of Defects" estimation model are: (constant $=1.63$ defects and 0.017 defects/CFP). Therefore, the Total Defect estimation model based on the complete dataset $N=49$ projects is:

Total Number of Defects $=1.63($ defects $)+0.017($ defects $/$ CEP $) *$ Functional Size $($ CFP $)$

It also can be observed from Table 6 that the $T$-test and the $P$-value are statistically significant. Table 6 also shows the coefficients of determination $\left(R^{2}\right)$ which is (0.5) for the TD estimation model (based on "Functional Size") that to be used for the imputation procedure. The confidence interval is (Lower Limit is 0.0113, and Upper Limit is 0.0225).

Figure 13 shows the distribution of the total defects based on complete dataset of $N=49$ software projects sized by COSMIC method, with a range from 1 defect to 63 defects, where $80 \%$ of values are less than or equal to 10 defects. The average is 10 defects.

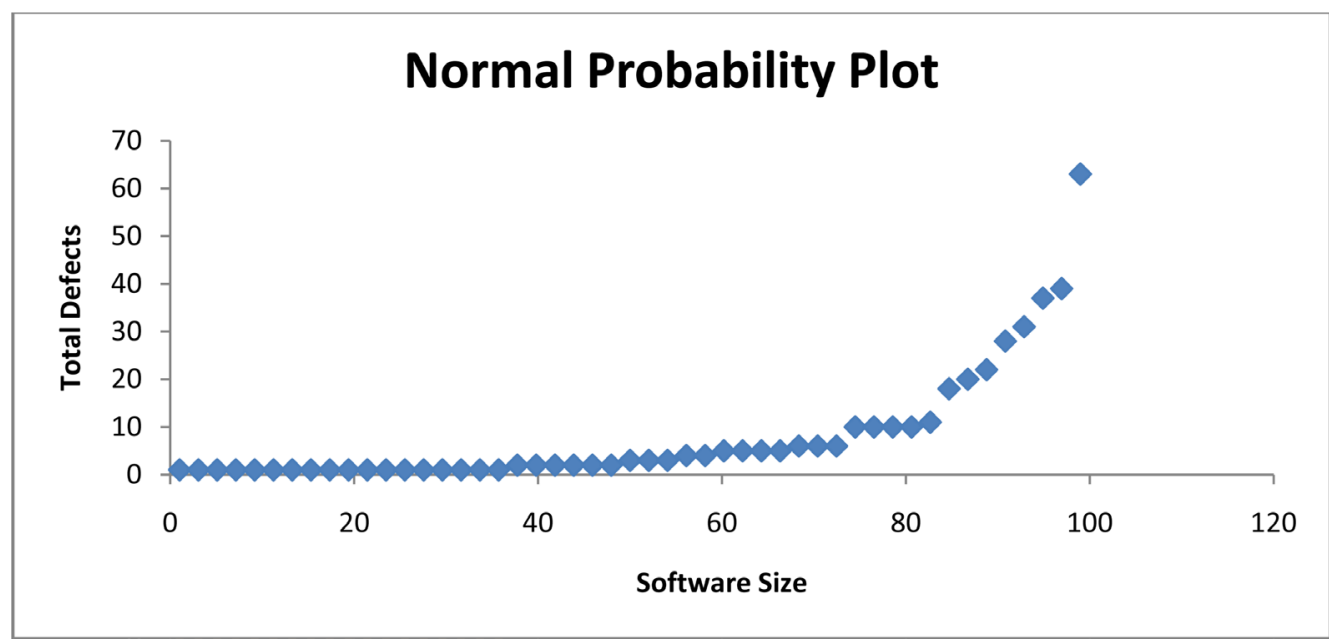

Figure 12. Normal probability plot of total defects and functional size based on the complete dataset $-N=49$.

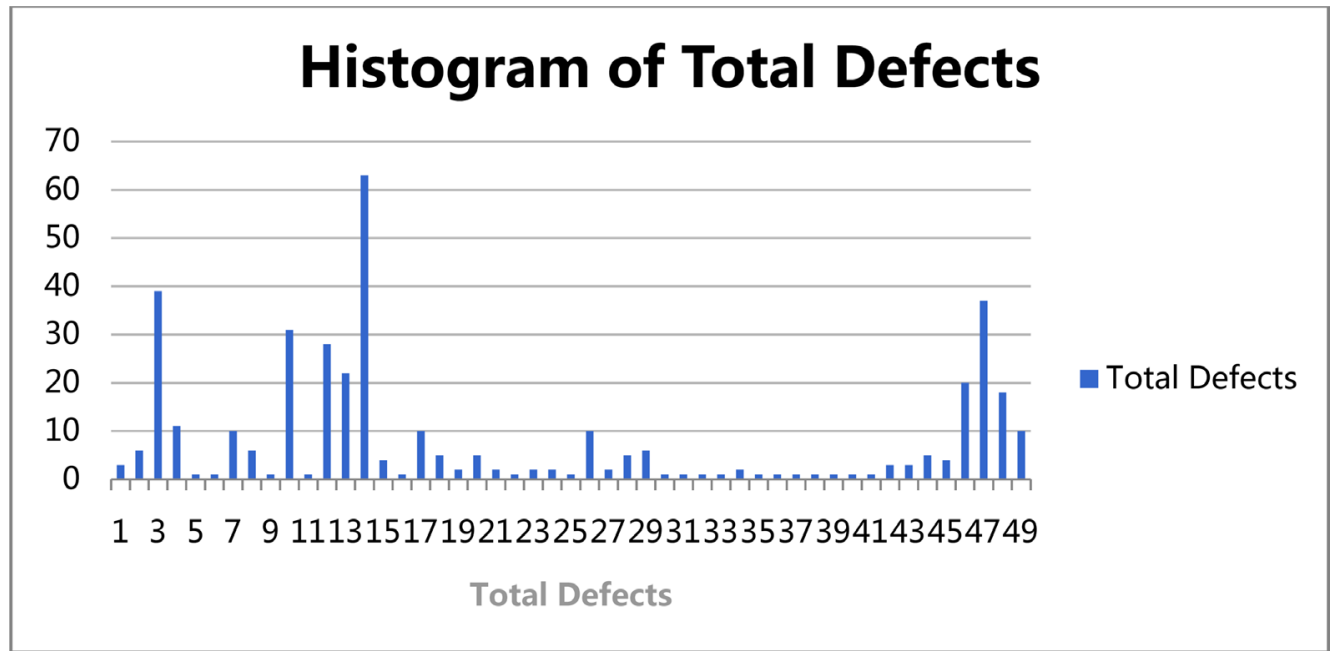

Figure 13. Total defects of complete dataset $-N=49$. 
Figure 14 shows the distribution of the software sizes based on complete dataset of $N=49$ software projects sized by COSMIC method, with a software size ranges from 11 CFP to 2003 CFP (COSMIC Function Points), with most values at the low end. The median is 186 CFP.

Figure 15 shows the distribution of the defect density based on complete dataset of $N=49$ software projects, with a range from 0.0012 Defects/CFP to 0.2093 Defects/CFP, The median is 0.0269 Defects/CFP.

Figure 16 shows the Sigma values for complete dataset $N=49$ software projects, with a range from 2.31 Sigma to 4.54 Sigma, and the average is 3.49 Sigma.

Software projects with ranging of Sigma values (e.g., from 3 Sigma to 4.5 Sigma) can be then used for building defect estimation models in terms of the independent variable "Functional Size": where higher levels of Sigma correspond to fewer defects, this implies higher levels of customer satisfaction.

\section{Conclusions and Future Work}

The study reported here has investigated the extent to which the ISBSG repository

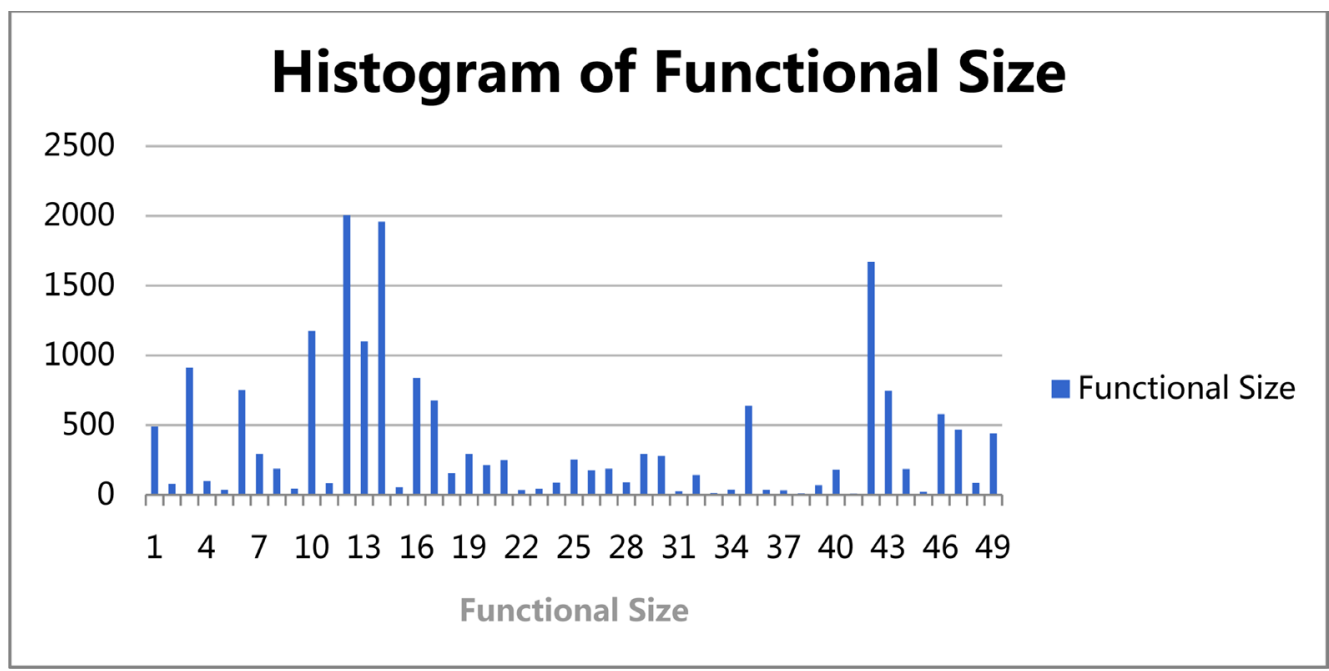

Figure 14. CFP software sizes of complete dataset, $N=49$ projects.

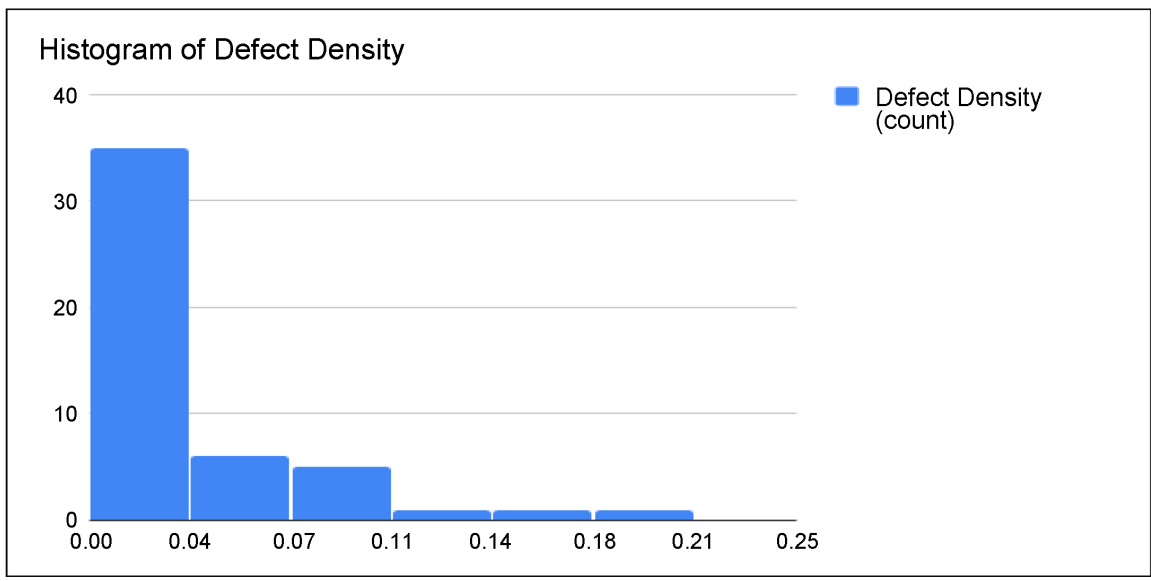

Figure 15. Defect density of complete dataset, $N=49$ projects. 


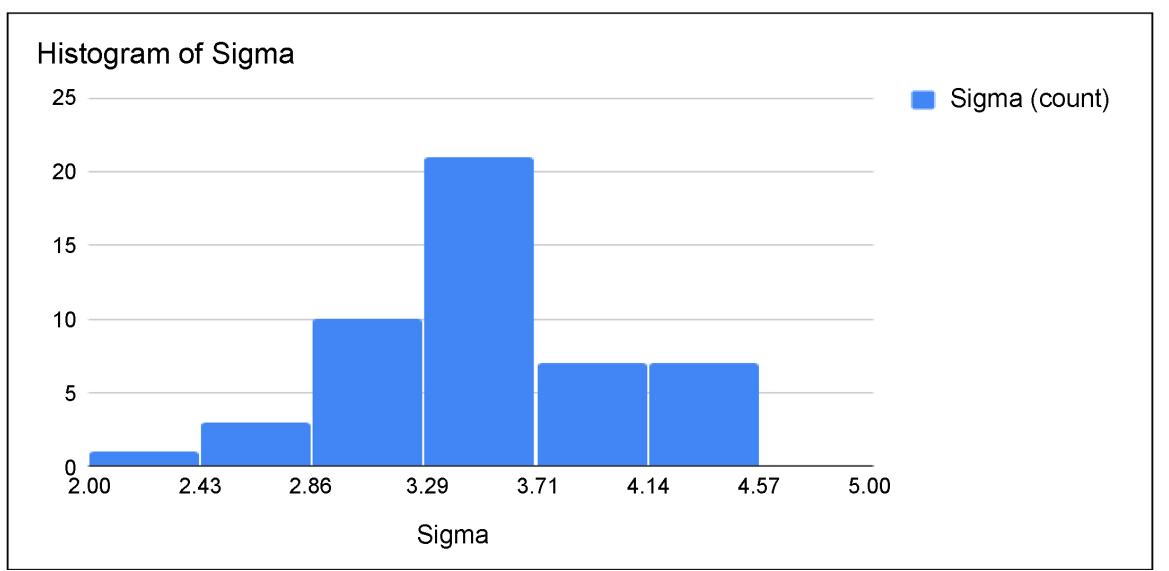

Figure 16. Sigma values of the complete dataset $-N=49$.

can be used in terms of some of the related Six Sigma measurement aspects such as Sigma defect measurement in the context of software defect estimation purposes. This study presented the quality-related information in the ISBSG questionnaire, and conducted mapping of the ISBSG questionnaire to the related measurement steps in Six Sigma (DMAIC and DFSS) methodologies. It presented the data set preparation consisting of two levels of data preparations based on [18], and then analyzed the quality-related data fields in the ISBSG MS-Excel data extract (Release 12 - 2013). It also presented an analysis of the extracted dataset of software projects.

This study has found that the ISBSG MS-Excel data extract (Release 12 - 2013) has a high ratio of missing data within the data fields of "Total Number of Defects" variable, which represents a serious challenge when the ISBSG dataset is being used for software defect estimation. Thus, the missing data problem was tackled using imputation technique in order to have complete datasets that could be useful for building defect estimation models. This study has also found that using the Sigma defect measurement aspects, such as the Sigma levels, which can be useful to improve designing software defect estimation models.

This study has found that:

- The parameter estimates for the "Total Number of Defects" estimation model using the complete dataset $N=49$ projects correspond to the following Total Defect estimation model:

Total Number of Defects $=1.63$ Defects +0.017 (Defects/CEP) $*$ Functional Size (CFP)

- The distribution of the total defects from the complete dataset of $N=49$ software projects had a range from 1 defect to 63 defects, where $80 \%$ of values were less than or equal to 10 defects. The average was 10 defects.

- The distribution of the software sizes from the complete dataset of $N=49$ software projects had a range from 11 CFP to 2003 CFP (COSMIC Function Points). The median was $186 \mathrm{CFP}$.

- The distribution of the defect density based on complete dataset of $N=49$ software projects, had a range from 0.0012 Defects/CFP to 0.2093 Defects/CFP, The median was 0.0269 Defects/CFP. 
- The Sigma values for complete dataset $N=49$ software projects, had a range from 2.31 Sigma to 4.54 Sigma, and the average was 3.49 Sigma.

- Software projects with a range of Sigma values (e.g., from 3 Sigma to 4.5 Sigma) can be then used for building defect estimation models in terms of the independent variable "Functional Size": whereas, higher levels of Sigma correspond to fewer defects, this implies higher levels of customer satisfaction.

Furthermore, this study can be very useful to the industry, researchers and practitioners in:

1) Analyzing the availability of the quality-related information in the ISBSG repository.

2) Preparing for detailed studies through requesting specific quality-related data fields form the ISBSG organization.

3) Improving the ISBSG repository in terms of the software quality-related data collections.

4) Investigating the usefulness of Sigma measurement-related aspects along with software defect estimation using the ISBSG repository. However, more studies are needed in order to clarify the use of such measurement aspects using the available software data repositories.

\section{References}

[1] Tonini, A.C., Spinola, M.D.M. and Laurindo, F.J.B. (2006) Six Sigma and Software Development Process: Dmaic Improvements. Technology Management for the Global Future, 6, 2815-2823. https://doi.org/10.1109/picmet.2006.296875

[2] Nanda, V. and Robinson, J. (2011) Six Sigma Software Quality Improvement. McGraw-Hill Education, New York.

[3] Wang, H. (2008) A Review of Six Sigma Approach: Methodology, Implementation and Future Research. Wireless Communications, Networking and Mobile Computing, Volume 1-4. https://doi.org/10.1109/wicom.2008.1887

[4] Feng, Q. (2008) Six Sigma: Continuous Improvement toward Excellence, in Collaborative Engineering. Springer, New York, 43-60. https://doi.org/10.1007/978-0-387-47321-5_3

[5] Antony, J. and Fergusson, C. (2004) Six Sigma in the Software Industry: Results from a Pilot Study. Managerial Auditing Journal, 19, 1025-1032. https://doi.org/10.1108/02686900410557926

[6] Teng, S.J. (2008) The Pros and Cons of Six Sigma Quality Management. Proceedings of International Conference on Advanced Information Technologies, Hanoi, 6-9 October 2008, 1-10.

[7] Al-Qutaish, R.E. and Al-Sarayreh, K.T. (2008) Applying Six-Sigma Concepts to the Software Engineering: Myths and Facts. Proceedings of the 7 th International Conference on Software Engineering Parallel and Distributed Systems, Cambridge, 2022 February 2008, 178-183.

[8] Hong, G. and Goh, T. (2003) Six Sigma in Software Quality. The TQM Magazine, 15, 364-373. https://doi.org/10.1108/09544780310502697

[9] Pan, Z., et al. (2007) A Six Sigma Framework for Software Process Improvements and Its Implementation. Proceedings of 14th Asia-Pacific Software Engineering 
Conference, 4-7 December 2007, 446-453. https://doi.org/10.1109/aspec.2007.43

[10] Motorola (2011) Free Six Sigma Lessons. http://web.archive.org/web/20051107013618/http://www.motorola.com/content/0,, 3069-5787,00.html\#

[11] Murugappan, M. and Keeni, G. (2000) Quality Improvement-The Six Sigma Way. Quality Software 2000 Proceedings of First Asia-Pacific Conference on IEEE, Hong Kong, 30-31 October 2000, 248-257. https://doi.org/10.1109/apaq.2000.883798

[12] Mahanti, R. and Antony, J. (2009) Six Sigma in the Indian Software Industry: Some Observations and Results from a Pilot Survey. The TQM Journal, 21, 549-564. https://doi.org/10.1108/17542730910995837

[13] International Software Benchmarking Standards Group (2013) ISBSG Development and Enhancement Repository R12. International Software Benchmarking Standards Group, Australia.

[14] Cukic, B. (2005) Guest Editor's Introduction: The Promise of Public Software Engineering Data Repositories. IEEE Software, 22, 20-22.

https://doi.org/10.1109/MS.2005.153

[15] Menzies, T. (2008) Improving IV\&V Techniques through the Analysis of Project Anomalies: LINKER-Preliminary Report. Agricultural \& Biological Chemistry, Volume 1-13, 11.

[16] Cheikhi, L. and Abran, A. (2013) Promise and ISBSG Software Engineering Data Repositories: A Survey. Joint Conference of the International Workshop on Software Measurement, 10, 17-24. https://doi.org/10.1109/iwsm-mensura.2013.13

[17] Cheikhi, L. (2008) Études Empiriques des Relations entre les Modèles de Qualité Du Logiciel D'iso 9126 en Utilisant le Référentiel de Données D'isbsg et la Méthode Taguchi. École de Technologie Supérieure, Montreal.

[18] Déry, D. and Abran, A. (2005) Investigation of the Effort Data Consistency in the ISBSG Repository. École de Technologie Supérieure, Montreal.

[19] Motorola (2011) What Is Six Sigma? http://www.intrarts.com/Motorola/index.shtml

[20] Kwak, Y.H. and Anbari, F.T. (2006) Benefits, Obstacles, and Future of Six Sigma Approach. Technovation, 26, 708-715. https://doi.org/10.1016/j.technovation.2004.10.003

[21] Heckl, D., Moormann, J. and Rosemann, M. (2010) Uptake and Success Factors of Six Sigma in the Financial Services Industry. Business Process Management Journal, 16, 436-472. https://doi.org/10.1108/14637151011049449

[22] Tennant, G. (2001) Six Sigma: SPC and TQM in Manufacturing and Services. Gower Publishing, Farnham.

[23] Isixsigma (2014) 1.5 Sigma Process Shift. https://www.isixsigma.com/new-to-six-sigma/dmaic/15-sigma-process-shift/

[24] Tayntor, C.B. (2007) Six Sigma Software Development. CRC Press, Boca Raton. https://doi.org/10.1201/9781420044287

[25] Shaout, D.A. and El-Haik, D.B. (2008) Software Design for Six Sigma: A Roadmap for Excellence. John Wiley Press, Hoboken.

[26] Cheikhi, L., Abran, A. and Buglione, L. (2006) ISBSG Software Project Repository \& ISO 9126: An Opportunity for Quality Benchmarking. European Journal for the Informatics Professional, 7, 46-52.

[27] Symons, C. and Lesterhuis, A. (2014) Introduction to the COSMIC Method of 
Measuring Software. The COSMIC Measurement Practices Committee.

[28] Cheikhi, L., Abran, A. and Buglione, L. (2007) The ISBSG Software Project Repository: An Analysis from the ISO 9126 Quality Perspective. Software Quality Professional, 9, 4-24. 


\section{Appendix A: ISBSG Data Fields with Information Related to Software Quality}

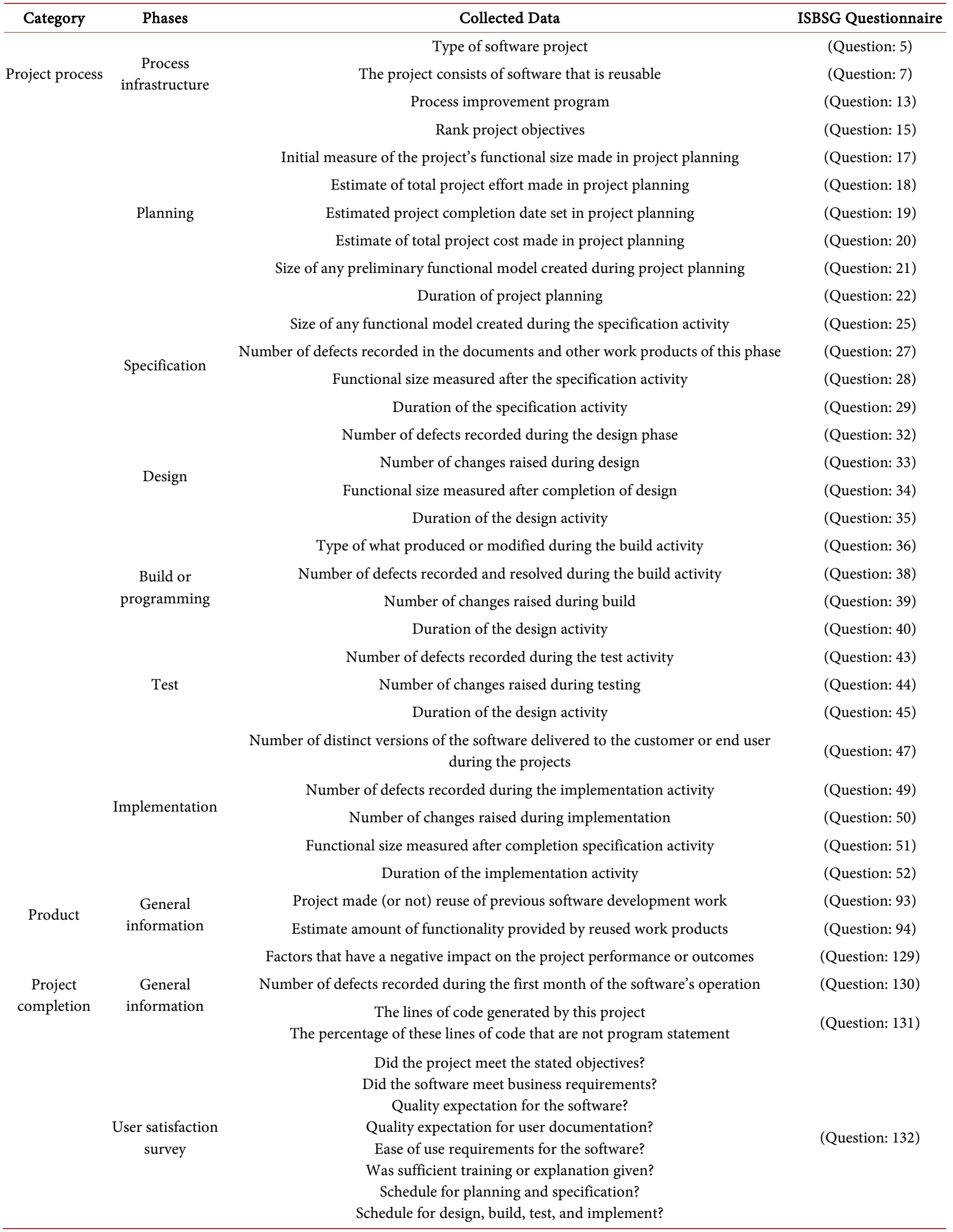




\section{Continued}

\section{Appendix B: Mapping ISBSG Questionnaire Sections to Six}

Sigma

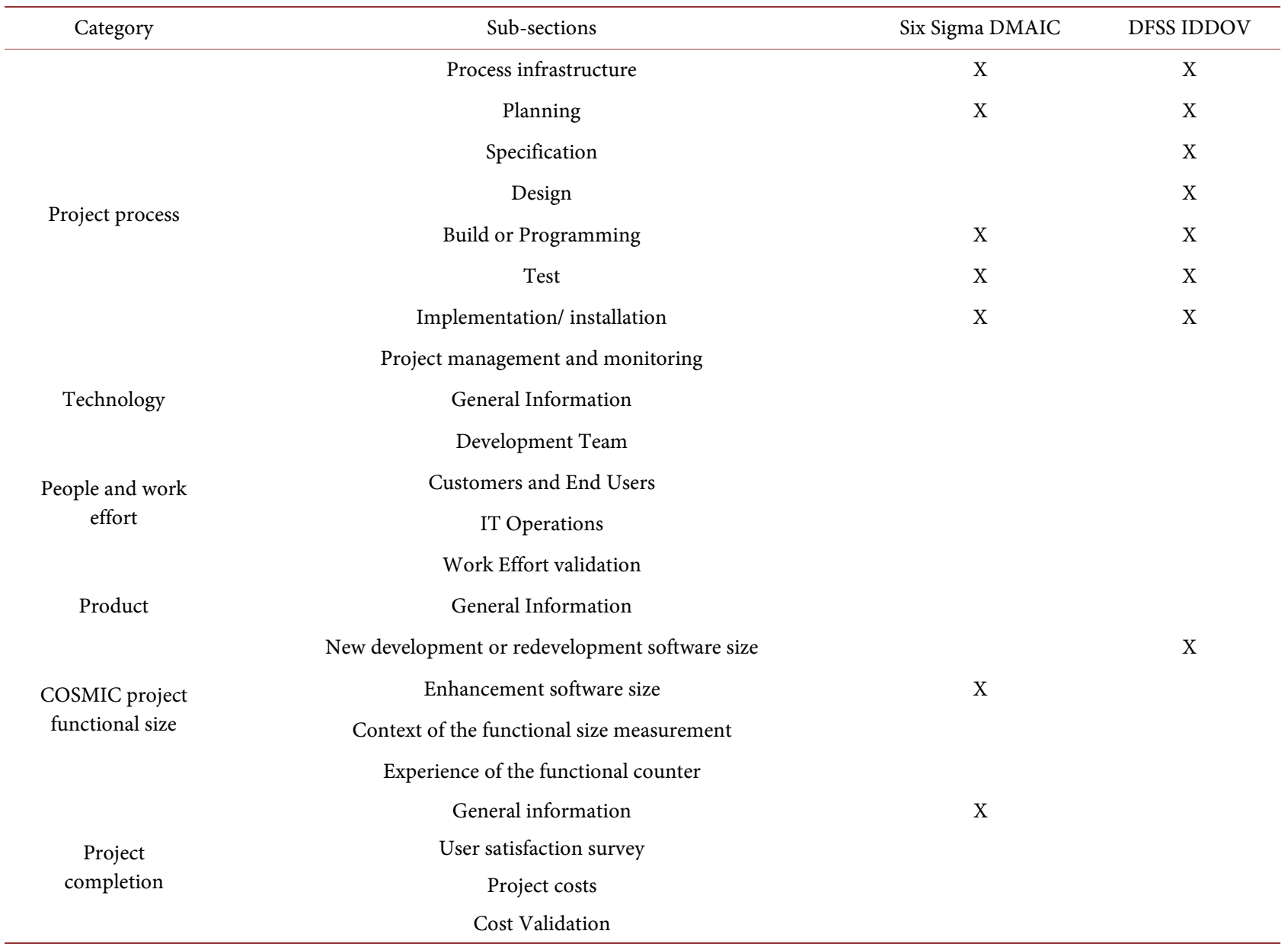

\section{Appendix C: Detailed Six Sigma Views in in the ISBSG Data Collection Questionnaire}

\begin{tabular}{|c|c|c|c|c|c|}
\hline Category & Phases & Collected Data & $\begin{array}{c}\text { ISBSG } \\
\text { Questionnaire }\end{array}$ & $\begin{array}{l}\text { Six Sigma } \\
\text { DMAIC }\end{array}$ & $\begin{array}{l}\text { DFSS } \\
\text { IDDOV }\end{array}$ \\
\hline \multirow{7}{*}{$\begin{array}{l}\text { Project } \\
\text { process }\end{array}$} & \multirow{5}{*}{ Process infrastructure } & Type of software project & (Question: 5) & $\mathrm{X}$ & $\mathrm{X}$ \\
\hline & & The project consists of software that is reusable & (Question: 7) & & \\
\hline & & Process improvement program & (Question: 13) & $\mathrm{X}$ & $\mathrm{X}$ \\
\hline & & Rank project objectives & (Question: 15) & $\mathrm{X}$ & $\mathrm{X}$ \\
\hline & & $\begin{array}{l}\text { Initial measure of the project's functional size made in } \\
\text { project planning }\end{array}$ & (Question: 17) & & $\mathrm{X}$ \\
\hline & \multirow[t]{2}{*}{ Planning } & $\begin{array}{c}\text { Estimate of total project effort made in project } \\
\text { planning }\end{array}$ & (Question: 18) & & \\
\hline & & $\begin{array}{l}\text { Estimated project completion date set in project } \\
\text { planning }\end{array}$ & (Question: 19) & & \\
\hline
\end{tabular}




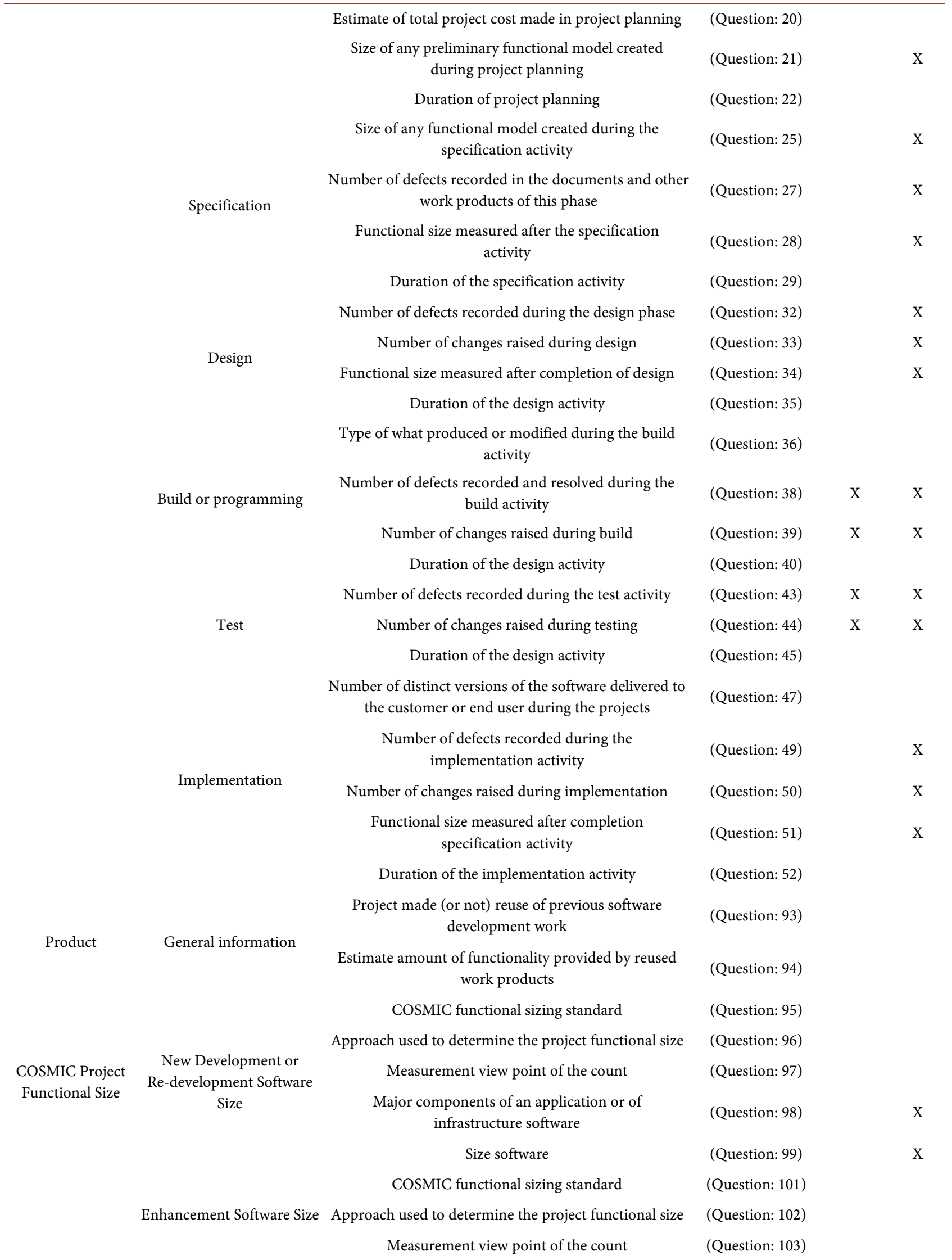




\section{Continued}

\section{Project completion \\ General information}

User satisfaction survey

$$
\begin{gathered}
\text { Functional size of the software before the } \\
\text { enhancement project }
\end{gathered}
$$

Major components of an application or of infrastructure software

Added functionality-size software

Changed functionality-size software

Deleted functionality-software

Software size in COSMIC function points

Total duration of the project

Total inactivity time on the project

Factors that have a positive impact on the project performance or outcomes

Factors that have a negative impact on the project performance or outcomes

Number of defects recorded during the first month of the software's operation

The lines of code generated by this project The percentage of these lines of code that are not program statement

Did the project meet the stated objectives? Did the software meet business requirement?

Quality expectation for the software? Quality expectation for user documentation? Ease of use requirements for the software? Was sufficient training or explanation given?

Schedule for planning and specification? Schedule for design, build, test, and implement?

Development team costs for each activity/total Customer/End-user costs for each activity/total IT operation costs for each activity/total
(Question: 104) X

(Question: 105) X

(Question: 106) X

(Question: 107) X

(Question: 108) X

(Question: 109) X

(Question: 126)

(Question: 127)

(Question: 128) X $\quad \mathrm{X}$

(Question: 129) X X

(Question: 130) X

(Question: 131)

(Question: 132)

(Question: 135)

Submit or recommend next manuscript to SCIRP and we will provide best service for you:

Accepting pre-submission inquiries through Email, Facebook, LinkedIn, Twitter, etc. A wide selection of journals (inclusive of 9 subjects, more than 200 journals)

Providing 24-hour high-quality service User-friendly online submission system Fair and swift peer-review system Efficient typesetting and proofreading procedure Display of the result of downloads and visits, as well as the number of cited articles Maximum dissemination of your research work

Submit your manuscript at: http://papersubmission.scirp.org/

Or contact jsea@scirp.org 